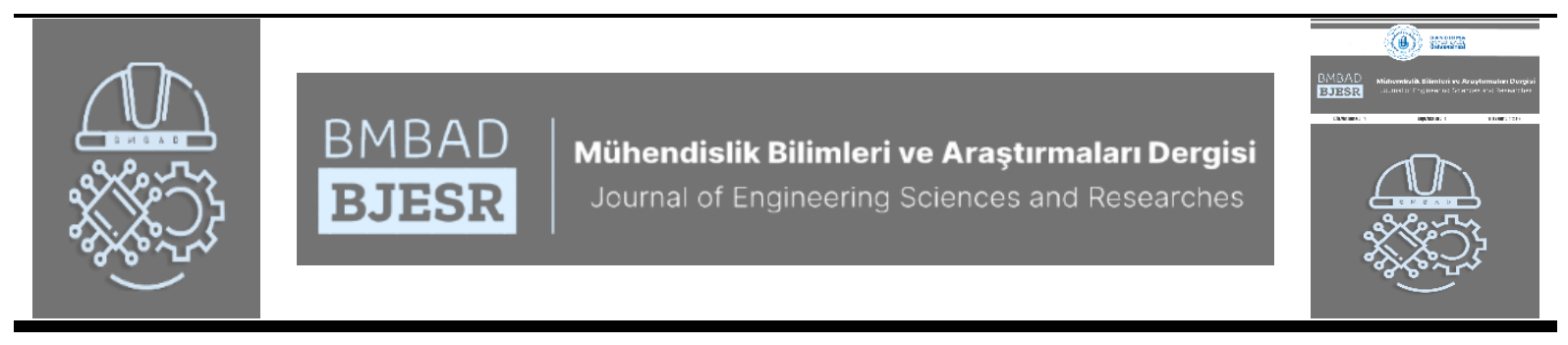

\title{
Uzun Kısa Dönem Bellek Ağlarını Kullanarak Erken Aşama Diyabet Tahmini
}

\author{
Early-Stage Diabetes Prediction Using Long Short-Term Memory Networks
}

İlyas ÖZER

Bandırma Onyedi Eylül Üniversitesi, Mühendislik ve Doğa Bilimleri Fakültesi, Bandırma/Balıkesir, Türkiye

iozer@bandirma.edu.tr

Araştırma Makalesi/Research Article

\begin{tabular}{l}
\hline ARTICLE INFO \\
Article history \\
Received :4 September 2020 \\
Accepted :23 September 2020
\end{tabular}

Keywords:

Diabetes, Long Short-Term

Memory Networks, Machine Learning

\begin{abstract}
Diabetes is one of the biggest health problems of today. If diabetes is detected late, it can cause serious complications such as kidney disorders, cardiac disorders, visual disturbances and amputation. In addition, this situation puts a considerable economic burden on the health system. On the other hand, diabetes can usually occur 7-12 years before it is clinically detected. In this study, a long short-term memory (LSTM) based approach is proposed for early detection of diabetes. The proposed approach was tested with 10-fold cross validation on a dataset of a total of 16 features, including age, sex, and 14 different symptom data from 520 patients. LSTM networks have been developed for sequence data that have time dependencies between each other. However, although the data used here has no temporal dependence, it is seen that the sequential processing of the fixed vectors of the data set improves the performance. As a result, compared to the prediction studies performed on the same data set, an improvement of $1.5 \%$ was achieved in the F1 score used to measure the accuracy of the test. As a result of 10-fold cross validation, an average F1 score of $98.9 \%$ was obtained.
\end{abstract}

C 2020 Bandirma Onyedi Eylul University, Faculty of Engineering and Natural Science. Published by Dergi Park. All rights reserved.

\section{ÖZET}

Diyabet, günümüzün en büyük sağl1k problemlerinden bir tanesidir. Diyabet hastalığının geç tespit edilmesi durumunda kişilerde böbrek rahatsızlıkları, kardiyak rahatsızlıklar, görme bozuklukları ve ampütasyon gibi çok ciddi komplikasyonlara neden olabilmektedir. Ayrıca bu durum sağlık sistemi üzerine önemli bir ekonomik yük getirmektedir. Öte yandan diyabet, genellikle klinik olarak tespitinden 7-12 yıl öncesine kadar ortaya çıkabilmektedir. Bu çalışmada diyabetin erken dönemde tespiti için uzun kısa dönem bellek (LSTM - Long Short-Term Memory) ağı tabanlı bir yaklaşım önerilmektedir. Önerilen yaklaşım, 520 hastadan elde edilmiş yaş, cinsiyet ve 14 farklı semptom verisi olmak üzere toplam 16 öznitelikten oluşan bir veri kümesi üzerinde 10-kat çapraz doğrulama ile test edilmiştir. LSTM ağları birbirleri arasında zamansal bağımlılı̆̆ olan dizi şeklindeki veriler için geliştirilmişlerdir. Bununla birlikte burada kullanılan verilerin zamansal bağımlılığı olmamasına rağmen, veri kümesinin sabit vektörlerinin sıralı bir şekilde işlenmesinin performansı artırdığı görülmektedir. Sonuç olarak aynı veri kümesi üzerinde gerçekleştirilen tahmin çalışmalarına kıyasla, testin doğruluğunu ölçebilmek için kullanılan F1 skorunda \%1,5'lik bir iyileşme sağlamıştır. 10-kat çapraz doğrulama sonucunda ortalama olarak \%98,9'luk bir F1 skoru elde edilmiştir.

(C) 2020 Bandırma Onyedi Eylül Üniversitesi, Mühendislik ve Dağa Bilimleri Fakültesi. Dergi Park tarafından yayınlanmaktadır. Tüm Hakları Saklıdır. 


\section{GÍRIŞ}

Diabetes Mellitus çağımızın en hızlı büyüyen kronik rahatsızlıklarından biridir. Coğrafi ırksal veya etnik bağlamdan bağımsız olarak hızla gelişen bu hastalık genellikle Tip 1 ve Tip 2 olmak üzere 2 gruba ayrılmaktadır. Tip 1 olarak adlandırılan diyabet türü bağışıklık sisteminin yanlışlıkla pankreas beta hücrelerine saldırmasıyla ortaya çıkar [1]. Bu durumda vücuda ya çok az miktarda insülin salınır veya hiç salınmaz. Tip 2 olarak adlandırılan diyabet türü ise, vücudun uygun miktarda insülin üretmemesine veya vücudun insüline karşı dirençli hale gelmesine bağlı olarak ortaya çıkar. Diğer bir grup araştırmacı diyabeti üç grup altında incelemektedir. Burada üçüncü tür gestasyonel diyabet olarak adlandırılır. Gebelik diyabeti olarak ta bilinen bu diyabet türü sadece gebelik dönemindeki hormonal değişiklikler sonucu ortaya çıkar [1]. Poliüri, polidipsi, polifaji, ani kilo kaybı (genellikle Tip 1), halsizlik, obezite (genellikle Tip 2), gecikmiş iyileşme, görsel bulanıklık, kaşıntı, sinirlilik, genital pamukçuk, kısmi parezi, kas sertliği ve alopesi diyabetin yaygın olarak görülen semptomlarıdır [1-3].

Dünya Sağlık Örgütü (WHO) verilerine göre dünya genelinde diyabetli hasta sayısı 1980 y1lında 108 milyon iken, zaman içerisinde çok hızlı bir artış kaydederek 2014 yılında 422 milyona ulaşmıştır [4]. Esasında çalışmalar diyabetin klinik tanıdan 7 ila 12 yıl öncesine kadar var olabileceğini ortaya koymaktadır [5,6]. Hastalığın ortaya çıkmasıyla klinik tanının konması arasındaki bu zaman dilimi içinde, insanlar yavaş yavaş felç, kalp krizi, körlüğe neden olan göz hasarı, ayak ülseri, etkilenen uzvun ampütasyonu, böbrek hasarı ve diğer çoklu organ hasarları gibi ölümcül komplikasyonlarla karşılaşabilirler [1,6]. Hastalığın tanısının konulması ve tedaviye başlanması sürecindeki gecikmeler komplikasyonun şiddetinin artmasına neden olmaktadır [1,6]. Ayrıca buna bağglı olarak tedavinin sağlık sistemi üzerine getirdiği ekonomik yükün boyutu da her geçen gün artmaktadır. Bu doğrultuda diyabetin erken dönemde tespiti son derece önemlidir.

Semptom, vücut kitle indeksi, yaş vb. verilerden diyabetin erken dönemde teşhisi için hekimlere yardımcı olabilecek sistemlerin geliştirilmesi oldukça önemlidir. Bu noktada makine öğrenmesi algoritmaları iyi bir çözüm olabilir. Makine öğrenmesi, bir grup veri üzerinden otomatik olarak öğrenebilen ve açık programlama [7-11] olmadan kalıpları algılayabilen yapay zeka uygulamalarıdır. Makine öğrenimi, herhangi bir görevi gerçekleştirmek için geleneksel algoritmaları kullanmanın zor olduğu veya mümkün olmadığ birçok durumda başarıyla kullanılmıştır. Makine öğreniminin en önemli avantajlarından biri, özellikler arasındaki karmaşık ve doğrusal olmayan ilişkileri kullanarak tutarlı ve yüksek performanslı tahminler yapabilmesidir [12]. Buna göre, doğrudan insanlar tarafindan görülemeyen karmaşık ilişkileri belirleyebilirler.

Joshi ve Chawan [13] tarafindan yapılan çalışmada glikoz, yaş, kan basıncı ve vücut kitle indeksi gibi 7 farklı öznitelik kullanılarak diyabet tahmini gerçekleştirilmiştir. Çalışmada [13], makine öğrenmesi algoritması olarak destek vektör makinesi (DVM), lojistik regresyon ve yapay sinir ağlarını (YSA) kullanmışlardır. En iyi sınıflandırma performansını DVM ile elde etmişlerdir. 25 ile 78 yaş arasındaki 250 hastaya ait veriler kullanılarak Sapon ve diğerleri [14] tarafindan gerçekleştirilen çalışmada, Bayesian Regülasyon algoritması ile \%88,8'lik bir sınıflandırma başarımı elde etmişlerdir. Tip 2 diyabet tahmini için Ahmed [15] tarafından gerçekleștirilen çalışmada da hastanın cinsiyeti, yaşı, sigara içime durumu, hipertansiyon geçmişi, böbrek problemi, kardiyak problemi ve göz problemi olmak üzere 9 farklı öznitelik kullanılmıştır. J48 algoritması ile \% 70,8'lik bir başarım değeri elde etmişlerdir.

Bu çalışmada, hastaların diyabetli olma durumunu tahmin etmek için makine öğrenmesi tabanlı bir yaklaşım önerilmektedir. Böylelikle karar verme sürecinde hekimlerin elindeki veri miktarının artırılması ve kaynakların daha etkin kullanılması amaçlanmaktadır. Ayrıca diyabetin erken dönemde teşhisine yardımcı olarak hastaların maruz kalabileceği komplikasyonların azaltılması hedeflenmektedir. Bunlara ilave olarak, literatürdeki çalışmalarda diyabet tahmini yaygın olarak DVM, YSA ve karar ağaçları gibi geleneksel makine öğrenmesi algoritmaları kullanılmaktadır. Bu çalışmada derin öğrenme tabanlı bir algoritma olan uzun kısa dönem bellek ağları (LSTM) ile tahmin işlemi gerçekleştirilmektedir. Elde edilen sonuçlar potansiyel olarak umut vericidir.

\section{MATERYAL VE METOTLAR}

\subsection{Veri Kümesi Tanımı}

Kullanılan veri kümesi, 520 kişiye ait diyabetle ilgili semptomlarının raporlarını içermektedir. Bu raporlar içerisinde diyabetin belirtileri olabilecek semptomlara sahip insanlar hakkındaki veriler bulunmaktadır. Bu veri kümesi, yakın zamanda diyabetik olan veya hala diyabetik olmayan ancak birkaç veya daha fazla semptomu olan kişilerle doğrudan yapılan bir anketten oluşturulmuştur [1]. Veriler, Bangladeş Sylhet Sylhet Diyabet Hastanesinden doğrudan anket yöntemi kullanılarak hastalardan toplanmıştır [1]. Bu veri kümesi, UCI Makine Öğrenmesi Deposu [16] üzerinde halka açık şekilde yayınlanmıştır. 
Tablo 1. Özellik tanımlamaları

\begin{tabular}{l|c}
\hline Özellik & Değerler \\
\hline Yaş & 1.20-35, 2. 36-45, 3. 46-55, 4. 56-65, 5. 65 üstü \\
\hline Cinsiyet & 1. Erkek, 2. Kadın \\
\hline Poliüri & 1. Evet, 2. Hayır \\
\hline Polidipsi & 1. Evet, 2. Hayır \\
\hline Ani kilo kaybı & 1. Evet, 2. Hayır \\
\hline Halsizlik & 1. Evet, 2. Hayır \\
\hline Polifaji & 1. Evet, 2. Hayır \\
\hline Genital Pamukçuk & 1. Evet, 2. Hayır \\
\hline Görsel Bulanılık & 1. Evet, 2. Hayır \\
\hline Kaşıntı & 1. Evet, 2. Hayır \\
\hline Sinirlilik & 1. Evet, 2. Hayır \\
\hline Geç İyileşme & 1. Evet, 2. Hayır \\
\hline Kısmi Parezi & 1. Evet, 2. Hayır \\
\hline Kas Sertliği & 1. Evet, 2. Hayır \\
\hline Alopesi & 1. Evet, 2. Hayır \\
\hline Obezite & 1. Evet, 2. Hayır \\
\hline Sınıf & 1. Pozitif, 2. Negatif \\
\hline
\end{tabular}

Veri kümesi Tablo 1'de detayları da belirtilen 16 özellik ve 1 bir sınıf bilgisinden oluşmaktadır. Sınıf bilgisinde pozitif durum hastada diyabet bulunduğu anlamına gelirken negatif durum diyabet olmadığı anlamına gelmektedir. Veri kümesinde 200 negatif sınıf 320 pozitif sınıf bulunmaktadır. Yaş özelliği 5 farklı durum altında kategorize edilmiştir. Diğer özelliklerin tamamı 2 ayrı durumdan oluşmaktadır. Durum bilgilerinde "Evet" semptomun bulunduğu anlamına gelirken "Hayır" değeri de semptomun bulunmadığı anlamına gelmektedir.

\subsection{Uzun Kısa Dönem Bellek Ağları}

Yapay sinir ağları (YSA) makine öğrenimi uygulamalarında çok geniş bir kullanım alanına sahiptir [17-21]. Farklı ihtiyaçlar doğrultusunda zaman içerisinde birçok YSA modeli geliştirilmiştir. Bu doğrultuda bazı YSA'lar farklı veri türlerini işlemek için uzmanlaşmıştır. Evrişimli sinir ağları, görüntü gibi matris tipi veriler için yaygın olarak kullanılmaya başlanmıştır. Öte yandan, dizi türündeki verileri işlemek için tekrarlayan sinir ağları (Recurrent Neural Network-RNN) geliştirilmiştir. Geleneksel ileri beslemeli YSA'lar, girdi olarak sadece maruz kaldıkları mevcut örnekleri dikkate alır. RNN'ler ise bunlardan farklı olarak mevcut girdilerin yanı sıra zaman içerisinde algıladıkları örnekleri de girdi olarak kullanırlar.

$x_{i} \in R^{d}$ olmak üzere $\left[x_{1}, x_{2}, \ldots, x_{k}\right]$ şeklinde bir dizi verilmiş olsun. Burada k değeri dizi uzunluğuna bağlı olarak değişkenlik gösterebilir. RNN her adımında, $\left[h_{1}, h_{2}, \ldots, h_{k}\right]$ şeklinde bir gizli durum dizisi meydana getirir. Gizli durumun t zamanındaki aktivasyonu, mevcut giriş $x_{t}$ ve önceki gizli durum $h_{t-1}$ 'in bir fonksiyonu olarak hesaplanır. Bu süreci şu şekilde ifade etmek mümkündür:

$h_{t}=f\left(x_{t}, h_{t-1}\right)$

Geleneksel ileri beslemeli YSA'nın aksine, RNN'lerin bir tekrar katmanı vardır. Bu katman aracılığıyla, ileri beslemeli ağ tarafından üretilen durum bilgisi depolanır ve giriş bilgisi ile ağa yeniden uygulanır. Yani, RNN'lerin şimdiye kadar hesaplananları tutan bir hafızası vardır. Şekil 1 ve Şekil 2, sırasıyla örnek bir RNN ağını ve bu ağın açı gösterimini göstermektedir. 


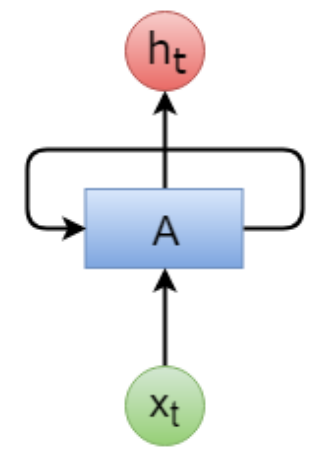

Şekil 1. Tekrarlayan Sinir Ağının kapalı gösterimi [21]
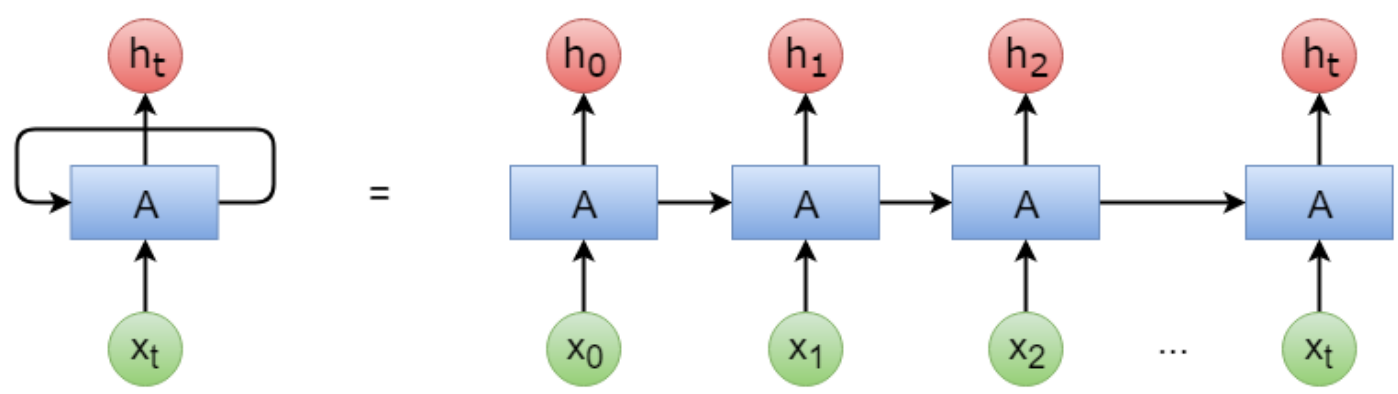

Şekil 2. Tekrarlayan Sinir A ğının açık gösterimi [21]

Genellikle LSTM (Long Short-Term Memory Network) olarak adlandırılan uzun kısa dönem bellek ağları, uzun vadeli bağımlılıkları öğrenebilen özel bir RNN türüdür. İlk olarak 90'ların ortalarında [23] önerilen bu model günümüzde yaygın olarak kullanılmaktadır. RNN'lerde diziler işlenirken, YSA'nın durum bilgilerinin saklanması ve aktarılması amaçlanmaktadır. Ancak, durum bilgilerinin sürekli işlenerek aktarılması sonucunda uzun vadeli bağımlılıkları bozmadan aktarılması pek olası değildir. Diğer bir deyişle, kısa vadeli bağımlılıklar çok başarılı bir şekilde aktarılırken, uzun vadeli bağımlılıkların aktarılmasında sorunlar yaşanmaktadır. LSTM'ler, uzun vadeli bağımlılık sorunlarını ele almak için tasarlanmıştır. Kısa vadeli bağımlılıklar Şekil 3 'te görülürken, uzun vadeli bağımlılıklar Şekil 4'te görülmektedir.

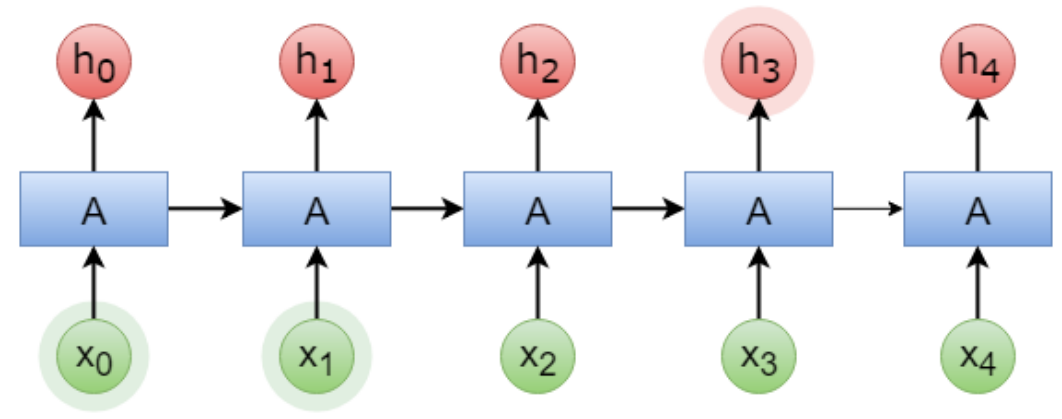

Şekil 3. Kısa vadeli bağımlılıklar [21]

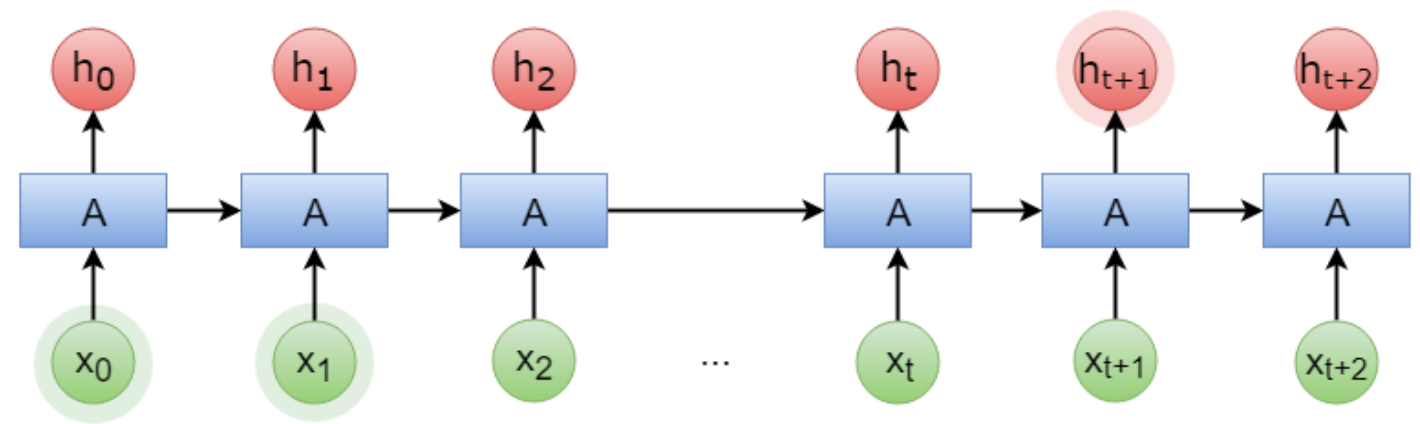

Şekil 4. Uzun vadeli bağımlılıklar [21] 
Tüm RNN ağları bir zincir gibi tekrar eden modüllerden oluşur. Standart RNN'lerde, bu modüllerin her biri genellikle bir tanh fonksiyonundan veya benzer bir fonksiyondan oluşur. Şekil 5, standart bir RNN'nin modül yapısını göstermektedir. LSTM'leri standart RNN'lerden ayıran özellik, bu modülün iç yapısının Şekil 6'da görüldüğü gibi birbiriyle etkileşen 4 ayrı yapıdan oluşmasıdır.

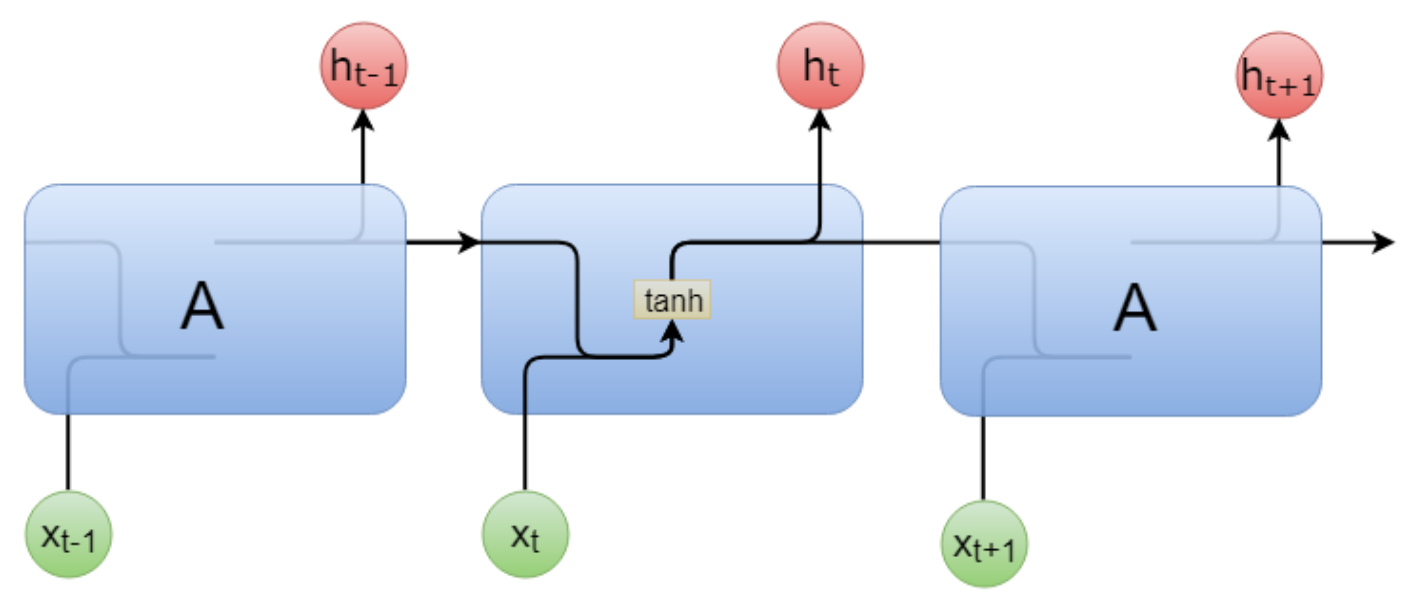

Şekil 5. Standart RNN yapısı [21]

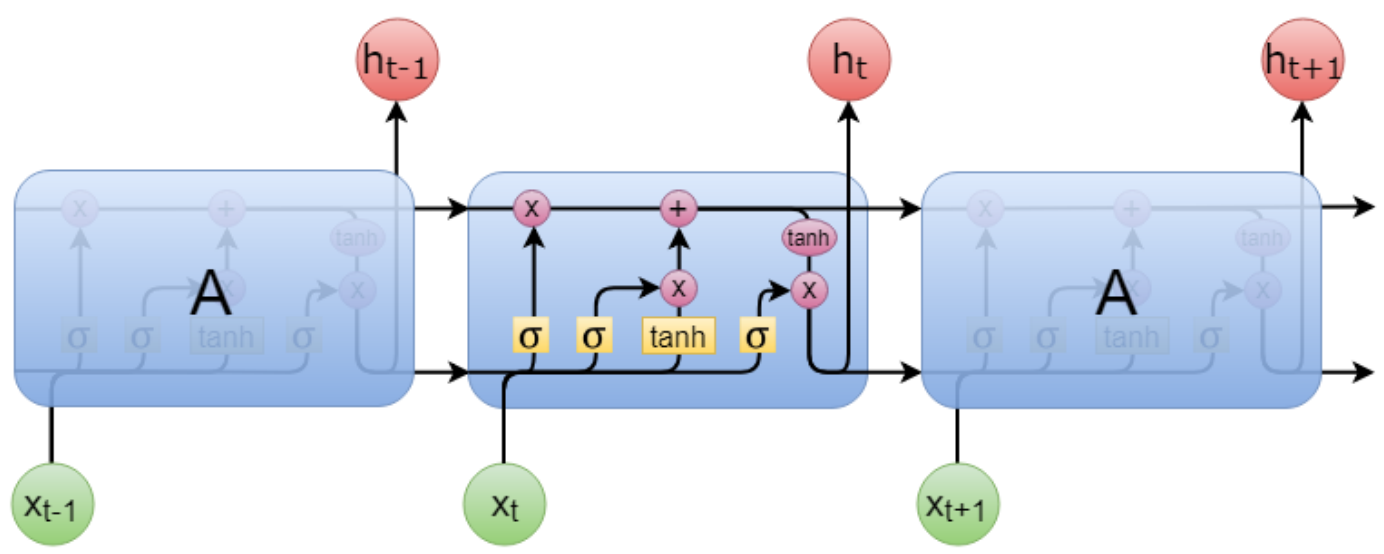

Şekil 6. LSTM yapısı [21]

LSTM modülü 3 ayrı kapıdan oluşur. Bunlar sırasıyla unutma kapsısı, giriş kapsı ve çıkış kapısıdır. Unutma kapıları, bilgilerin ne kadarının unutulacağına ve ne kadarının bir sonraki aşamaya aktarılacağına karar verir. Bu işlem için, 0 ile 1 arasında bir değer üreten sigmoid fonksiyonu kullanır. 0, bilginin asla iletilmeyeceği anlamına gelirken, 1, hepsinin iletilmesi gerektiği anlamına gelir. Bir sonraki adım, hangi bilgilerin depolanması gerektiğine karar vermektir. Bu işlem giriş kapısındaki sigmoid fonksiyonu ile gerçekleştirilir. Tanh fonksiyonu daha sonra $\tilde{C}_{t}$ olarak ifade edilen aday değerlerin bir vektörünü oluşturur. Daha sonra bu iki süreç birleştirilir. Bu işlemden sonra bellek hücresinin yeni durum bilgisi hesaplanır. Son olarak, sistemin çıktısı hesaplanır. Bu işlemler matematiksel olarak şu şekilde ifade edilebilir:

$$
\begin{aligned}
& i_{t}=\sigma\left(W_{i} \cdot\left[h_{t-1}, x_{t}\right]+b_{i}\right) \\
& \tilde{C}_{t}=\tanh \left(W_{C} \cdot\left[h_{t-1}, x_{t}\right]+b_{C}\right) \\
& C_{t}=f_{t} * C_{t-1}+i_{t} * \tilde{C}_{t} \\
& o_{t}=\sigma\left(W_{o} \cdot\left[h_{t-1}, x_{t}\right]+b_{o}\right) \\
& h_{t}=o_{t} * \tanh \left(C_{t}\right)
\end{aligned}
$$




\subsection{Performans Değerlendirme Ölçütleri}

Performans değerlendirme ölçütleri, veri madenciliği modellerinden elde edilen sonuçları kıyaslamak için kullanılan önemli parametrelerdir. Veri madenciliği alanında, elde edilen sonuçları literatürdeki ilgili çalışmalarla karşılaştırmak için kullanılan geçerli birçok ölçüt vardır. Bu amaçla, bu çalışmada k-kat çapraz doğrulama, başarım, hassasiyet, kesinlik ve F1 skoru gibi çeşitli metrikler kullanılmıştır.

Veri madenciliği çalışmalarında, uygulanan modellerin başarısını değerlendirmek için veri kümesi eğitim ve test kümelerine ayrılmaktadır. Bu ayırma işlemi için kullanılan farklı yöntemler bulunmaktadır. K-kat çapraz doğrulama, sınıflandırma modellerinin eğitimi ve değerlendirilmesi için veri kümesini ayırmak için kullanılan en yaygın yaklaşımlarından bir tanesidir. K-kat çapraz doğrulama yönteminde, önce bir $\mathrm{k}$ değeri belirlenir. Veri kümesi belirtilen $\mathrm{k}$ değerine bağlı olarak parçalara bölündükten sonra, $\mathrm{k}$-kat çapraz doğrulama sistemi kullanılmaya başlanır. Verinin bir kısmı test için seçilir ve geri kalan kısmı da eğitim için kullanılır. Bu işlem belirlenen $\mathrm{k}$ değeri kadar tekrarlanır. Her adımda, daha önce test için kullanılmayan veri kümesinin 1 / $\mathrm{k}$ kısmı test için kullanılırken geri kalanı eğitim için kullanılır. Veri kümesindeki her örnek hem eğitim için hem de test için kullanılmış olur. Bu nedenle $\mathrm{k}$ farklı test sonucu elde edilmiştir. Sonuçların ortalaması modelin test doğruluğunu verir. $\mathrm{Bu}$ çalışmada, ağların performansını değerlendirmek 10 kat çapraz doğrulama kullanılmıştır. Önerilen algoritmaların değerlendirilmesinde, $\mathrm{k}$ kat çapraz doğrulamayla birlikte, başarım, kesinlik, hassasiyet ve F1 skoru ölçütleri kullanılmıştır. Kullanılan performans değerlendirme ölçütleri matematiksel olarak şu şekilde ifade edilebilir:

$$
\begin{aligned}
\text { Başarım } & =\frac{D P+D N}{D P+D N+Y P+Y N} \\
\text { Kesinlik } & =\frac{D P}{D P+Y P}
\end{aligned}
$$

Hassasiyet $=\frac{D P}{D P+Y N}$

$F 1=2 \cdot \frac{\text { Kesinlik. Hassasiyet }}{\text { Kesinlik }+ \text { Hassasiyet }}$

Burada;

Doğru Pozitif (DP): Diyabetik hastalar için diyabetik karar sayısı,

Doğru Negatif (DN): Diyabetik olmayanlar için diyabetik olmayan kararların sayısı,

Yanlış Pozitif (YP): Diyabetik olmayanlar için diyabetik kararların sayısı,

Yanlış Negatif (YN): Diyabetik hastalar için diyabetik olmayan kararların sayısını ifade eder.

\section{SONUÇLAR VE TARTIŞMA}

Bu çalışmada, 16 farklı öznitelik kullanılarak 520 farklı bireyin diyabetli olup olmama durumu tahmin edilmiştir. Sınıflandırma işlemi için iki ayrı gizli katmandan oluşan bir LSTM ağı kullanılmıştır. Her bir katman 100 üniteden meydana gelmektedir. Sınıflandırma doğruluğunun kıyaslanması için 10-kat çapraz doğrulama yöntemi kullanılmıştır. Bu işlemde öncelikli olarak veri 10 eşit parçaya bölünmüş ver her defasında parçalardan biri ile test işlemi gerçekleştirilirken geri kalan kısımlar eğitim için kullanılmıştır. Tablo 2'de her bir parçaya ait hassasiyet, kesinlik, F1 ve başarım değerleri verilmiştir. Bunun yanı sıra yine Tablo 2'de 10-kat çapraz doğrulama işleminin ortalama sonuçları görülmektedir.

Tablo 2'deki sonuçlar değerlendirildiğinde, her bir parça arasındaki veri dağılımının birbirini dışlayan nitelikte rasgele olarak gerçekleştiği ve bunun sonucunda da her bir parça arasındaki doğruluk değerlerinin birbirine benzer olduğu görülmektedir. Hassasiyet, kesinlik, F1 ve başarım değerleri için ortalama skorlarda sırasıyla \%99,37, $\% 98,43, \% 98,9$ ve $\% 98,65$ değerleri elde edilmiştir. 
Tablo 2. 10-kat çapraz doğrulama sonuçları

\begin{tabular}{rcccc}
\hline & Hassasiyet $(\boldsymbol{\%})$ & Kesinlik $(\boldsymbol{\%})$ & F1 $(\boldsymbol{\%})$ & Başarım (\%) \\
\hline Kat 1 & 95,83 & 95,83 & 95,83 & 96,15 \\
Kat 2 & 96,77 & 100,0 & 98,36 & 98,08 \\
Kat 3 & 100,0 & 96,43 & 98,18 & 98,08 \\
Kat 4 & 100,0 & 100,0 & 100,0 & 100,0 \\
Kat 5 & 100,0 & 97,06 & 98,51 & 98,08 \\
Kat 6 & 100,0 & 100,0 & 100,0 & 100,0 \\
Kat 7 & 100,0 & 100,0 & 100,0 & 100,0 \\
Kat 8 & 100,0 & 100,0 & 100,0 & 100,0 \\
Kat 9 & 100,0 & 96,67 & 98,31 & 98,08 \\
Kat 10 & 100,0 & 97,06 & 98,51 & 98,08 \\
\hline Ortalama & 99,37 & 98,43 & 98,9 & 98,65 \\
\hline
\end{tabular}

Tablo 3'te aynı veri seti üzerinde farklı algoritmalar ile gerçekleştirilen 10-kat çapraz doğrulama sonuçları görülmektedir. Buna göre diğer çalışmada [1] en iyi performansı \%97,4'lük F1 değeri ile "Random Forest" algoritması gösterirken en kötü sonucu ise \%87,5'lik F1 değeri ile Naive Bayes algoritması göstermiştir. Bu çalı̧̧mada kullanılan LSTM modeli diğer çalışmadaki en iyi F1 skoruna kıyasla \%1,5'lik bir iyileşme sağlamıştır. LSTM ağları yaygın olarak birbirleri arasında zamansal bağımlılığı olan dizi şeklindeki veriler için kullanılırlar. Burada kullanılan diyabet verilerin zamansal bağımlılı̆̆ olmamasına rağmen, veri kümesinin sabit vektörlerinin sıralı bir şekilde işlenmesinin performansı artırdığı görülmektedir. Dolayısıyla, girdileriniz ve çıktılarınız sabit vektörler olsa bile, bu güçlü biçimciliği onları sıralı bir şekilde işlemek için kullanmak hala mümkündür ve bunun performansı artırdığı görülmektedir.

Tablo 3. Diyabet veri kümesi üzerinde elde edilen sonuçlar

\begin{tabular}{ccccc}
\hline Çalışmalar & Yöntemler & Hassasiyet (\%) & Kesinlik (\%) & F1 (\%) \\
\hline & Naive Bayes & 87,4 & 87,9 & 87,5 \\
[1] & Lojistik regresyon & 92,4 & 92,4 & 92,4 \\
& J48 & 95,6 & 95,7 & 95,6 \\
& Random Forest & 97,4 & 97,4 & 97,4 \\
\hline Bu çalışma & LSTM & $\mathbf{9 9 , 3 7}$ & $\mathbf{9 8 , 4 3}$ & $\mathbf{9 8 , 9}$ \\
\hline
\end{tabular}

\section{Teşekkür}

M M Faniqul Islam, Rahatara Ferdousi, Sadikur Rahman ve Humayra Yasmin Bushra'ya veri kümelerini halka açık şekilde paylaşarak verdikleri bilimsel katkıdan dolayı teşekkür ederim.

\section{KAYNAKÇA}

[1] Islam, M. F., Ferdousi, R., Rahman, S., \& Bushra, H. Y. Likelihood prediction of diabetes at early stage using data mining techniques. In Computer Vision and Machine Intelligence in Medical Image Analysis pp. 113-125, Springer, Singapore, 2020.

[2] The 6 Different Types of Diabetes, The diabetic journey. https://thediabeticjourney.com/the-6different-types-of-diabetes. 2018.

[3] Statistics About Diabetes: American Diabetes Association, https://www.diabetes.org, 2018.

[4] Diabetes, World Health Organization (WHO):https://www.who.int/news-room/factsheets/detail/diabetes, 2018.

[5] Failure to detect type 2 diabetes early costing $\$ 700$ million per year, Diabetes Australia, https://www.diabetesaustralia.com.au, 2018.

[6] Harris, M. I., Klein, R., Welborn, T. A., \& Knuiman, M. W. Onset of NIDDM occurs at least 4-7 yr before clinical diagnosis. Diabetes care, vol.15, no. 7, pp. 815-819, 1998.

[7] C. M. Bishop, Pattern Recognition and Machine Learning Springer-Verlag New York. Inc. Secaucus, NJ, USA. 2006.

[8] A. L. Samuel, "Some Studies in Machine Learning Using the Game of Checkers," IBM J. Res. Dev., vol. 3, no. 3, pp. 210-229, Jul. 1959. 
[9] W. S. Lima, E. Souto, K. El-Khatib, R. Jalali, and J. Gama, "Human activity recognition using inertial sensors in a smartphone: An overview," Sensors (Switzerland), vol. 19, no. 14, 2019.

[10] G. Zhong, X. Ling, and L. N. Wang, "From shallow feature learning to deep learning: Benefits from the width and depth of deep architectures," Wiley Interdiscip. Rev. Data Min. Knowl. Discov., vol. 9, no. 1, pp. 1-14, 2019.

[11] S. Chauhan, L. Vig, M. De Filippo De Grazia, M. Corbetta, S. Ahmad, and M. Zorzi, "A Comparison of Shallow and Deep Learning Methods for Predicting Cognitive Performance of Stroke Patients From MRI Lesion Images," Front. Neuroinform., vol. 13, pp. 112, 2019.

[12] T. Hastie, R. Tibshirani, and J. Friedman, The elements of statistical learning: data mining, inference, and prediction. 2009.

[13] Joshi, T. N., \& Chawan, P. P. M. Diabetes Prediction Using Machine Learning Techniques. Ijera, vol. 8, no.1, pp. 9-13, 2018.

[14] Sapon, M. A., Ismail, K., \& Zainudin, S. Prediction of diabetes by using artificial neural network. In Proceedings of the 2011 International Conference on Circuits, System and Simulation, Singapore Vol. 2829,2011 .

[15] Ahmed, T. M. Developing a predicted model for diabetes type 2 treatment plans by using data mining. Journal of Theoretical and Applied Information Technology, 90(2), 181, 2016.
[16] Dua, D. and Graff, C. UCI Machine Learning Repository [http://archive.ics.uci.edu/ml]. Irvine, CA: University of California, School of Information and Computer Science, 2019.

[17] Ozer, I., Ozer, Z., \& Findik, O. Noise robust sound event classification with convolutional neural network. Neurocomputing, vol. 272, pp. 505-512, 2018

[18] Ozer, Z., Ozer, I., \& Findik, O. Diacritic restoration of Turkish tweets with word2vec. Engineering Science and Technology, an International Journal, vol. 21, no. 6, pp. 1120-1127, 2018.

[19] Ozer, I., Ozer, Z., \& Findik, O. Lanczos kernel based spectrogram image features for sound classification. Procedia computer science, vol. 111, pp. 137-144, 2017.

[20] A. Yeşil, U. Çelik, F. Temurtaş, Yapay Sinir Ağları Yöntemi ile İkinci Kuşak Akım Taşıyıcının Performans Parametrelerinin Tahmin Edilmesi. Mühendislik Bilimleri ve Araştırmaları Dergisi, vol. 1, no. 1, pp. 13-23, 2019.

[21] Toptaş, B., Hanbay, D. Renksel ve Dokusal Özellikler Kullanarak Alev ve Alev Olmayan Görüntü Kesitlerinin Sınıflandırılması. Mühendislik Bilimleri ve Araştırmaları Dergisi, vol. 1, no. 1, pp. $1-12,2019$.

[22] Ozer, Z., "Trafik yorumlarının sınıflandırılmasında normalizasyonun etkisi”, Doktora Tezi, Karabük Üniversitesi Fen Bilimleri Enstitüsü, Karabük, 2019.

[23] Hochreiter, S., \& Schmidhuber, J. Long short-term memory. Neural computation, vol. 9, no. 8, pp.17351780, 1997. 